\title{
CT-guided stereotactic neurosurgery: experience in 24 cases with a new stereotactic system
}

\author{
DGT THOMAS, RE ANDERSON, GH du BOULAY* \\ From the Departments of Neurological Surgery and Radiology, National Hospitals for Nervous Diseases, \\ Queen Square and Maida Vale, London, UK
}

SUMmaRY Twenty-four cases have been operated upon using a prototype Brown-Roberts-Wells, CT-guided stereotactic neurosurgical system. This device has proved to be practical and flexible in clinical use. No CT scanner modifications were required, a fact which simplied its use in more than one hospital. Multiple targets can be biopsied with ease and relative safety. Drainage and other therapeutic procedures can be carried out with minimal hazard. Future applications of this system may include its use with NMR and PET images.

The widespread use of cranial computed tomography (CT) scanning has resulted in the diagnosis of an increased number of small lesions, many of which are in deep parts of the brain. Positive biopsy of some of these lesions may be difficult and hazardous. Determining the exact location of a small lesion seen only on CT scan is especially challenging when no familiar ventricular or bony landmarks lie near the lesion. The purpose of this report is to present initial experience with a prototype stereotactic system which allows the neurosurgeon to transfer the geometric accuracy inherent in the CT scan image directly to the biopsy procedure, whilst retaining wide flexibility in the choice of skull entry point and pathway through the brain.

\section{Stereotactic frame}

\section{(a) Design and development}

Several stereotactic neurosurgical systems have been devised which integrate $C T$ scan data with the surgical planning procedure. ${ }^{1-6}$ The "BRW" system, named after its developers Brown, Roberts and Wells, which is manufactured by Trent Wells, Inc, Southgate, California and distributed by Radionics Inc, Burlington, Massachusetts,

\footnotetext{
*Present address: Department of Radiology, University of Utah Medical Center, Salt Lake City 84132, USA.

\begin{abstract}
Address for reprint requests: Mr DGT Thomas, Department of Neurological Surgery, The National Hospital, Queen Square, London, WC1 3BG UK.
\end{abstract}

Received 13 April 1983. Accepted 17 July 1983
USA and RDG Electro Medical Equipment, Croydon, Surrey, UK, was used exclusively in this study..$^{7-10}$

Starting with neurosurgical functional specifications, Brown developed a new design using computer graphics techniques. A lucite model of the proposed frame was then made which was tested by scanning it together with various lucite targets. The scan images were then used to determine the locations of the targets which could be approached from any angle with a mean error of $1.8 \mathrm{~mm} .^{9}$ After further extensive design development a metal frame was produced, and clinical trials were begun at the University of Utah. ${ }^{811}$ A similar system was put into use at the National Hospitals, London, in 1981.

\section{(b) Operative method}

After induction of general anaesthesia the head is shaved partially or fully as necessary, and the base ring is attached by four conically pointed metal screws mounted as adjustable carbon fibre arms. The surgical arc is clamped to the base ring and a blunt probe is brought into contact with the desired entry point on the scalp (fig 1 ). The $X, Y$ and $Z$ coordinate of this entry point are then determined by attaching the surgical arc to an identical base ring on a simulator device (fig 2). The patient is then transferred to the CT scanner couch were a localising frame is attached to the base ring (fig 3 ). The exact position and angle of the base ring is not critical, provided it lies on the skull below the level of the lesion. The nine rods spaced around the circumference of the frame produce dots in the CT scan image. The six vertical rods indicate the position of the target in relation to the base ring circumference. The position of the image of each oblique rod in relation to each pair of vertical rods provides points of reference in the depth (" $Z$ ") axis (fig 4).

After the target planes have been scanned, the patient is taken to the operating theatre where a burrhole is made at the previously chosen skull entry point. If it seems more appropriate an alternative skull entry point can be chosen at this stage. 


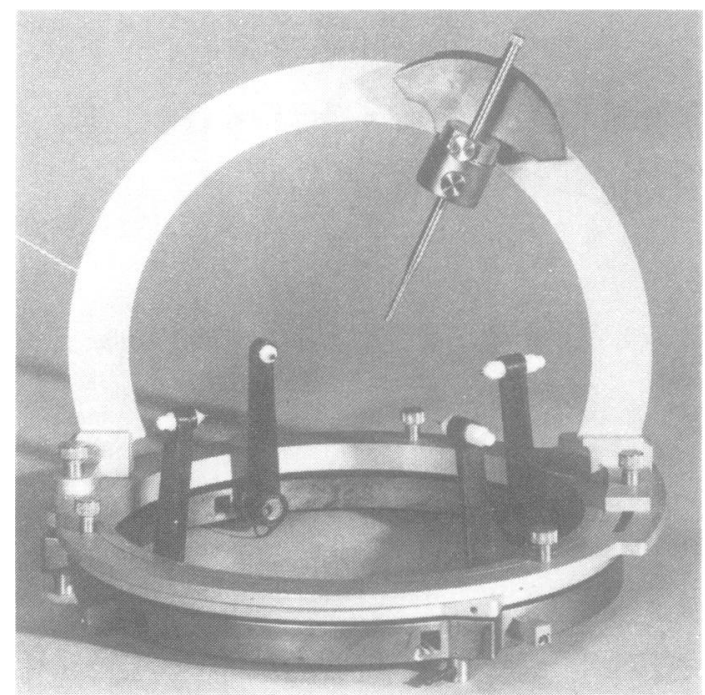

Fig 1 After base ring is fixed to the skull by means of four pins, the surgical arc is attached and a blunt probe brought in contact with the desired entry point on the skull.

$\mathrm{X}$ and $\mathrm{Y}$ coordinates are found for all nine localising rods and the target points by placing a transparent $1 \mathrm{~mm}$ grid over a large format film copy of the target scan. These values, along with the $\mathrm{X}, \mathrm{Y}$ and $\mathrm{Z}$ coordinates of the skull entry point, are entered into a small programmable printing calculator, Hewlett-Packard $41 \mathrm{C}$, which is supplied with soft ware as an integral part of the "BRW" system.

Four numerical surgical arc settings and a probe depth reading are produced by the calculator, and set by the

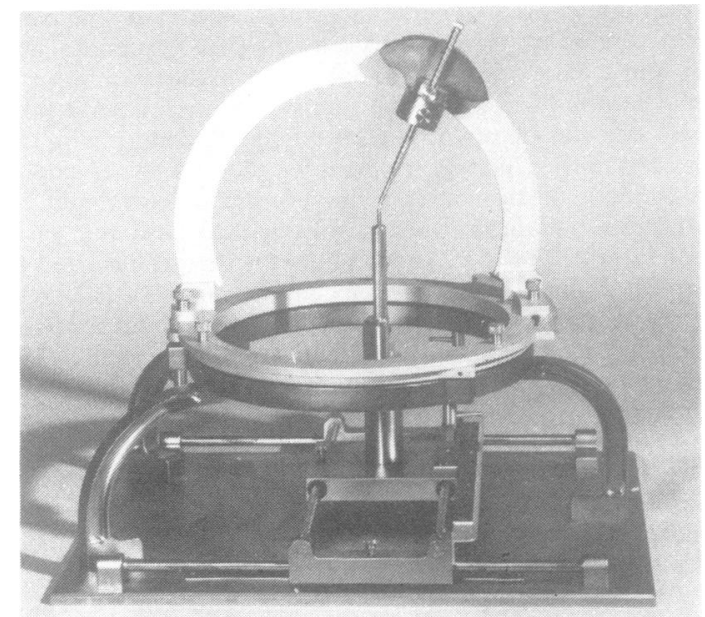

Fig 2 The surgical arc is then transferred to a simulator, where the $X, Y$, and $Z$ co-ordinates of the chosen skull entry point are determined.

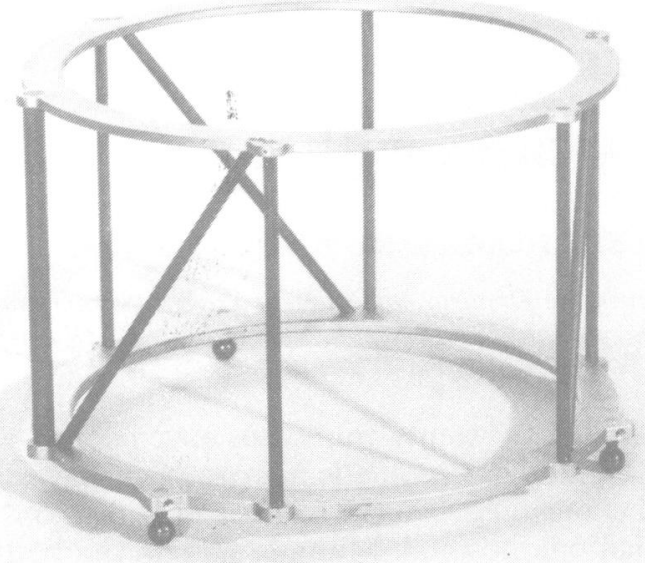

Fig 3 CT localising frame attached to base ring. The three oblique rods provide data regarding the position and angulation of the CT scan plane in relation to the base ring.

surgeon on the apparatus. $\mathrm{X}, \mathrm{Y}$ and $\mathrm{Z}$ values for the chosen target points are also printed so that one may check the accuracy of the biopsy plan using the simulator, prior to advancing the probe into the patient's brain. The appropriate biopsy cannula rongeur is then advanced through the guide tube to the set depth and multiple small tissue samples are then taken from one or more target sites and sent for laboratory study. Immediate smear frozen section paraffin embedded section, bacteriological culture, tissue culture, and chemical pathology analysis of cyst fluid, have been used as appropriate.

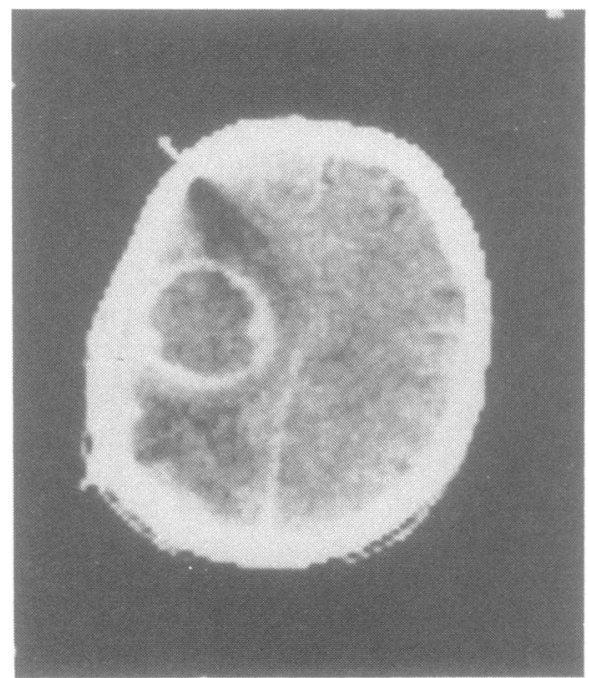

Fig 4 Images of the nine localising rods around the skull provide reference data linking the target lesion to the geometry of the stereotactic surgical frame. 


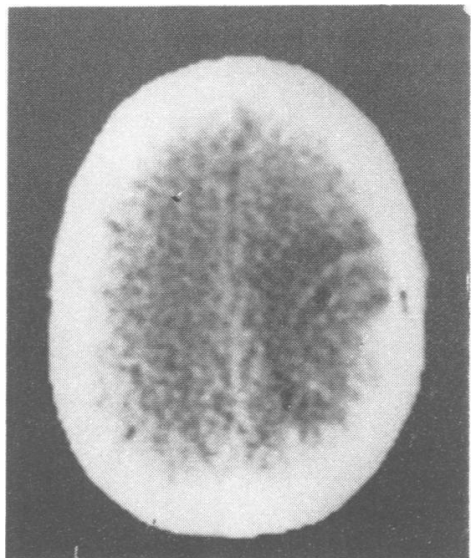

Fig 5 Follow up CT scan shows a small air bubble confirming the site of the biopsy.

Follow up scans, within one or two days, are very useful to show the position of the actual biopsy site (air bubble), degree of drainage of a cystic lesion, or haemorrhagic complication (fig 5).

\section{Results}

A summary of our initial results is presented in the table. Twenty-four CT-directed neurosurgical procedures have been performed at the time of writing. Eighteen were done for suspected tumour, 14 for the initial diagnosis and four for exclusion of radiation necrosis and histological re-grading of recurrences. Indications for use of this approach included small size of and, or, deep location of lesion, as well as dominant hemisphere site, the need to perform multiple biopsies in a presumably heterogenous

Table Results in 24 CT-directed neurosurgical procedures

\begin{tabular}{|c|c|c|}
\hline Clinical diagnosis & Number & Result \\
\hline Tumour & 18 & \\
\hline \multirow[t]{5}{*}{ Suspected primary tumour } & 14 & \\
\hline & 10 & Glioma \\
\hline & 1 & Infarct \\
\hline & $i$ & Hamartoma \\
\hline & 2 & $\begin{array}{l}\text { Failed-No histological } \\
\text { diagnosis reached }\end{array}$ \\
\hline \multirow[t]{3}{*}{ Suspected recurrent tumour } & 4 & \\
\hline & 3 & $\begin{array}{l}\text { Recurrent tumour (same } \\
\text { grade) }\end{array}$ \\
\hline & 1 & Radionecrosis \\
\hline Brain stem lesion & 1 & Granuloma \\
\hline Craniopharyngioma & $i$ & Cyst drainage \\
\hline Abscess & 2 & Drainage \\
\hline Haematoma & $\overline{1}$ & Drainage \\
\hline Functional & 1 & Brain stimulation \\
\hline Total & 24 & $\begin{array}{l}\text { Successful } \\
\text { Failed }\end{array}$ \\
\hline
\end{tabular}

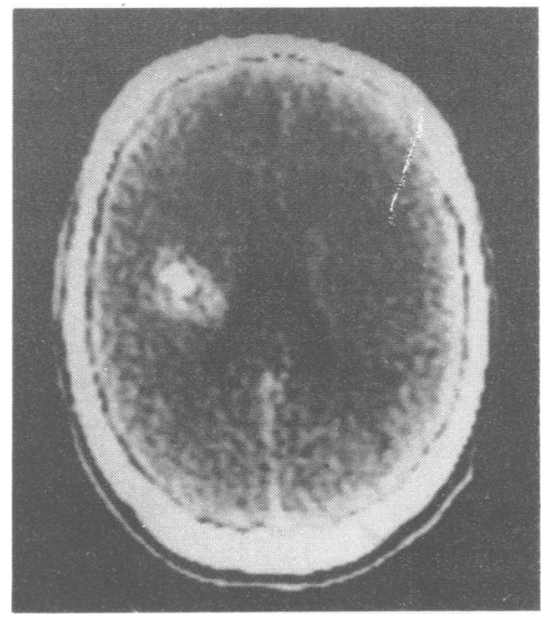

Fig 6 Dense, partially calcified, subcortical dominant hemisphere lesion in a 23-year-old male with increasing frequency of seizures. Biopsy showed hamartoma.

mass, the desire to drain a cystic lesion after biopsying the wall, and the wish to do the least hazardous procedure in a poor risk patient (figs 6-11)

Malignant tumours were diagnosed in 13 of these cases. One case each of infarct (fig 12), haematoma and radionecrosis were diagnosed. Biopsy samples failed to reveal neoplasm in two cases of presumed tumour.

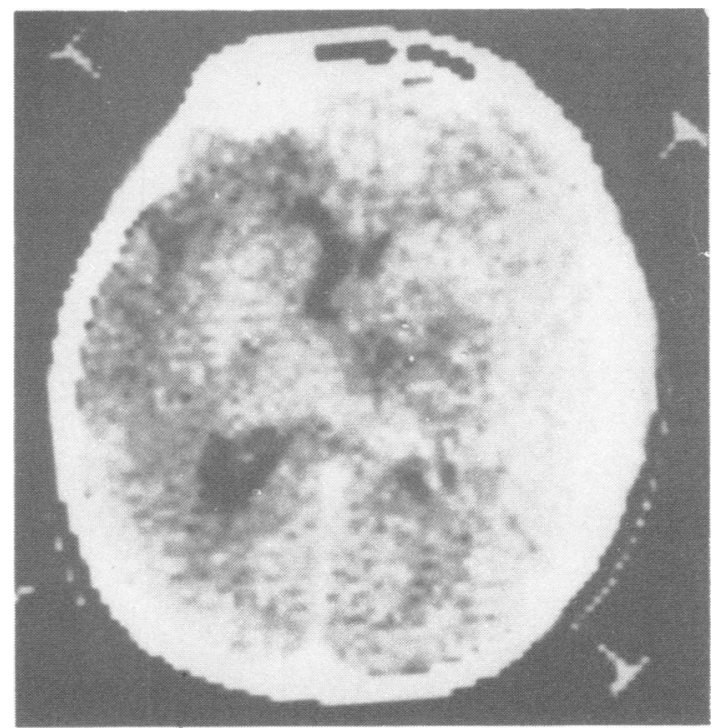

Fig 7 Deep, heterogenous mass in a 20-year-old female with multiple progressive symptoms and signs. Biopsy revealed low grade pilocytic astrocytoma. 


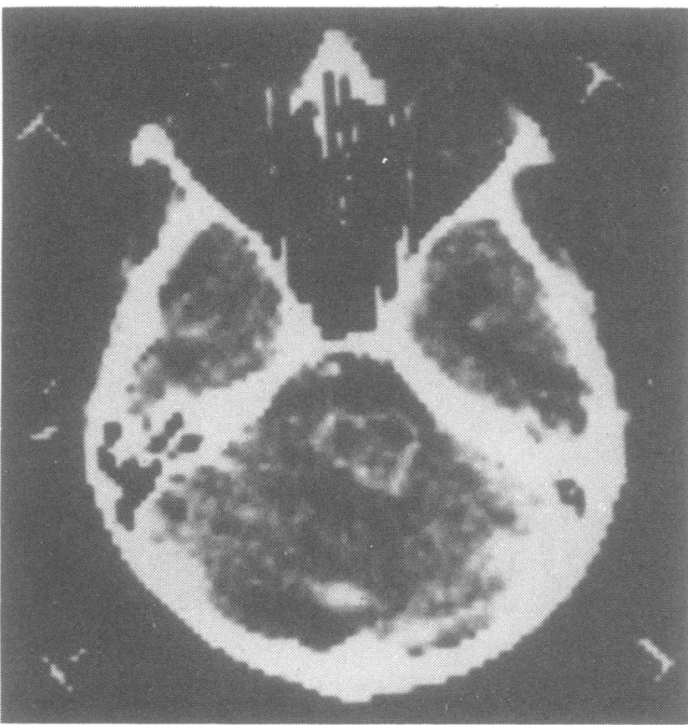

Fig 8 Enhancing ring lesion at the pontine level in a 36-year-old male with a non-caseating cutaneous granuloma. No tumour was found. Tissue specimen showed only non-specific reactive changes. Lesion was approached by a right frontal parasaggital route, without incident.

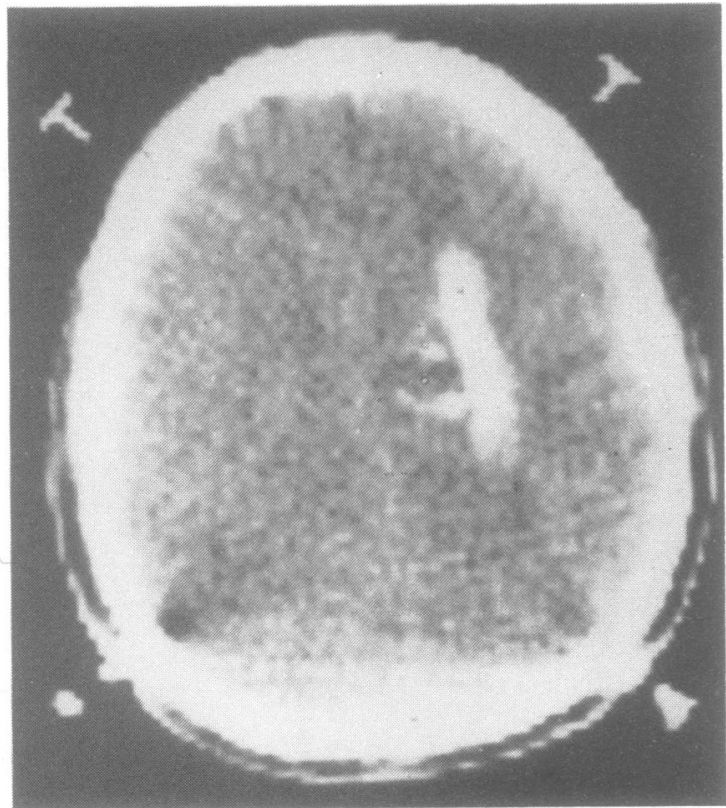

Fig 9 Deep, partially calcified lesion, in a 32-year-old man with seizures, having a very unusual configuration. Biopsy showed oligodendroglioma.

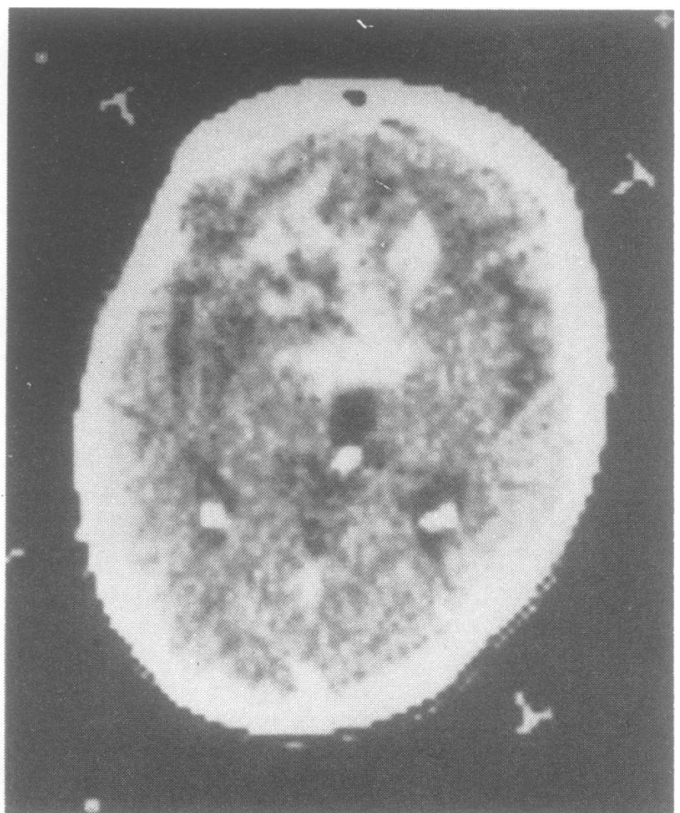

Fig 10 Heterogenous mass showing patchy enhancement is seen in a 44-year-old woman with known low grade astrocytoma. Biopsy was graded the same as the original tumour.

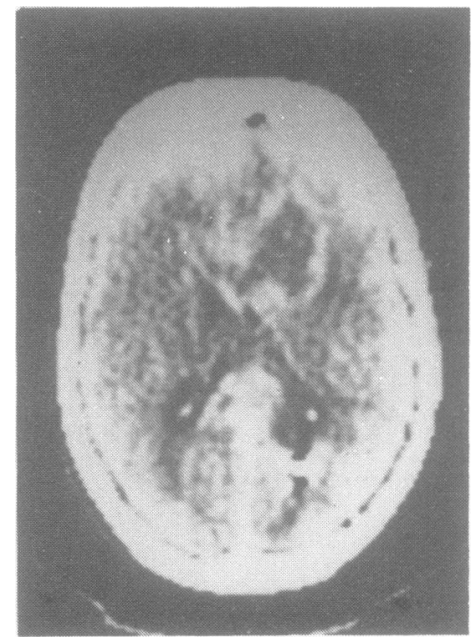

Fig 11 53-year-old patient with previous resection of a right occipital pole astrocytoma followed by radiotherapy. Biopsy of enhancing ring showed recurrent astrocytoma. 


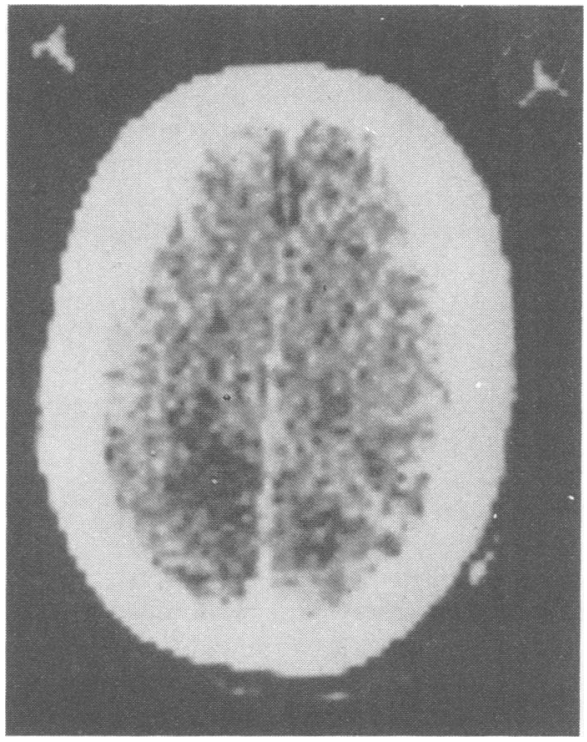

Fig 12 Progressive symptoms and an abnormal CT scan led to a request for biopsy in this 63-year-old man. Tissue from radiolucent zone was compatible with recent infarction.

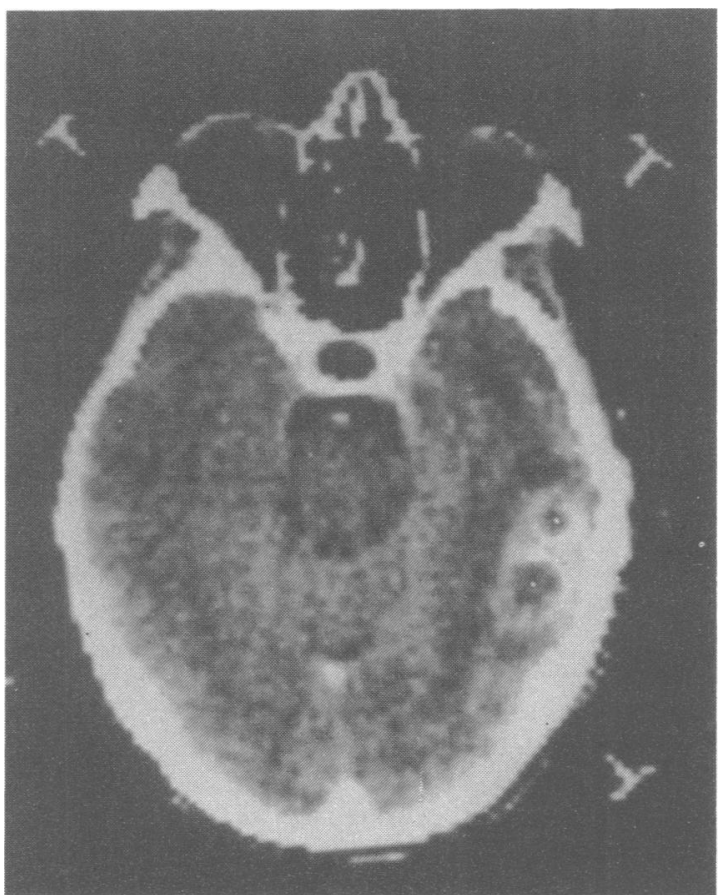

Fig 13 Previous craniotomy failed to obliterate these two abscess cavities in this 50-year-old female. The cavities were approached through the defect left from previous surgery and drained with single needle passes.

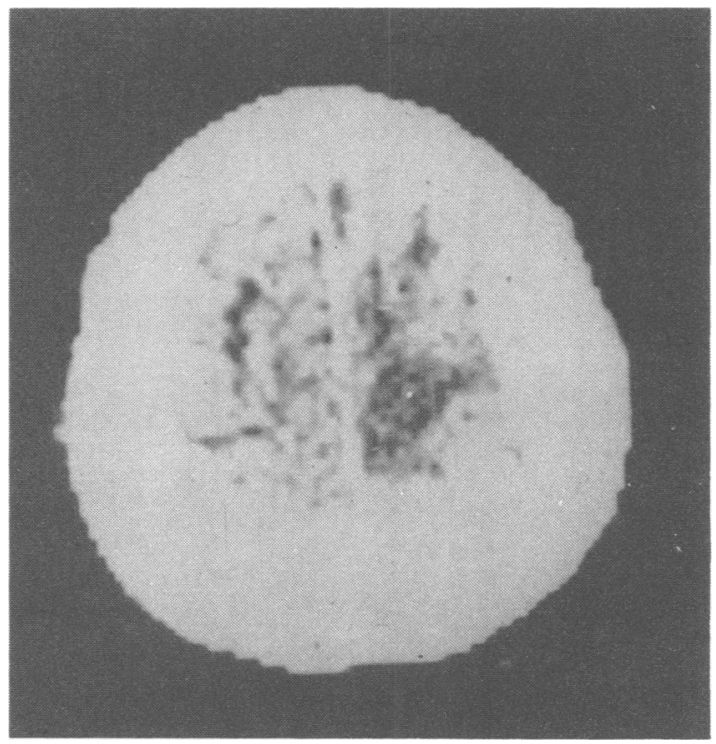

Fig 14 Progressive left leg. weakness in 48-year-old man led to CT scan and biopsy procedure, which was therapeutic in that an old dark haematoma was drained, with immediate improvement in his symptoms. No tumour was found.

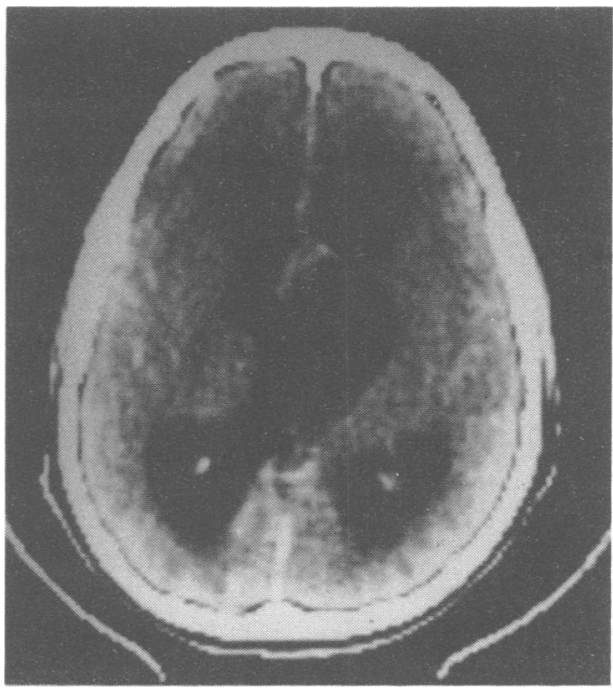

Fig 15 14-year-old boy with weakness and somnolence. Huge suprasellar cyst compresses hypothalamus and obstructs ventricles. $40 \mathrm{ml}$ of typical dark craniopharyngioma fuid drained via small needle. 


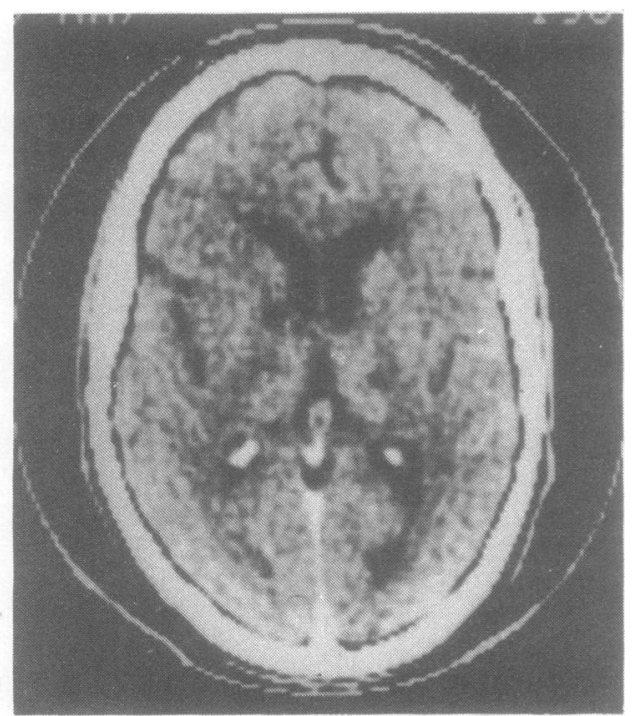

Fig 16 Man aged 50 yr with persistent pain after thalamotomy. Probe inserted to point medial to thalamotomy scar using surgical arc system.

Three abscesses in two patients were drained, as was one intracerebral haematoma (figs 13, 14). A pontine lesion, which proved negative for neoplasm and which resolved with drainage and antituberculous chemotherapy, was biopsied via a right frontal approach, without incident (fig 8). One large craniopharyngioma cyst was drained to relieve ventricular obstruction and hypothalamic compression (fig 15). A thalamic stimulation electrode was placed in the thalamus of a patient having persistent pain despite thalamotomy performed previously by conventional stereotaxis (fig 16). Two complications occurred. One patient developed a large haematoma after the stereotaxic procedure, but it is unclear whether the haematoma occurred secondary to the biopsies or from the insertion of a $3 \mathrm{~mm}$ fiberoptic endoscope into a cystic portion of the lesion through the stereotactic guide tube. Calculator failure occurred in one early case, necessitating a free hand biopsy in a relatively sensitive area. No further complication occurred in this patient. The biopsy was positive. No calculator problems have recurred.

\section{Discussion}

A tissue diagnosis is required prior to therapy for most cerebral mass lesions. In a study of 35 deep brain lesions, biopsied stereotactically, Broggi et al found that biopsy results changed their presumptive diagnosis in 10.12

The capability of the CT scanner to show small lesions anywhere in the brain has placed an increased burden on the neurosurgeon. Stereotactic methods seem ideally suited for biopsying these lesions. Ostertag et al, in reporting their experience with 302 cases of stereotactic biopsy state that "exploratory craniotomies, risky free-hand punctures and aspirations deep in the brain can no longer be advocated". ${ }^{13}$

Since most intracranial mass lesions significantly distort the normal brain anatomy, the actual CT scan of the target lesion is the obvious "map" to use in locating the lesion for biopsy, rather than intermediate radiological reference points, like the commissures of the third ventricle.

The "BRW" hardware differs from other CT compatible stereotactic systems in several respects. It was designed de novo as a CT-guided apparatus. The decisions to make the system independent of individual CT scanner calibration, as well as to be insensitive to patient position, have proved to have significant practical advantages. No attachment to the CT scanner or other modification of the CT gantry is needed. Any patient position which suits the patient's physique and the needs of the anaesthetist is satisfactory, provided that all nine localising rods are imaged on the CT section showing the target lesion (fig 4).

The original computer programs to determine surgical coordinates were designed to run in the CT scanner computer. In view of the wide range of computer hardware and software in use in different scanners this stategy was impractical. Two programmable calculators are now employed, the second serving as a back-up to the first. The program is stored permanently on a magnetic card and when required is loaded into the calculator. In describing this modification of the original system, Brown et $a l^{\text {" }}$ state that now the "system can be used with any CT scanner that can specify $(X, Y)$ coordinates of a pixel". The scanner, of an earlier CT generation, used in this study did not have this software feature. Therefore, a transparent $1 \mathrm{~mm}$ grid with $\mathrm{cm}$. numerals was made and used as an overlay, superimposed on large format film copies of the target scans (one image on a $20 \times 25 \mathrm{~cm}$ film). Phantom studies showed that target accuracy in the range of $2-3 \mathrm{~mm}$ was maintained using this procedure. Therefore, this system can be used in any wide aperture scanner capable of accommodating and imaging the head and surrounding localising rods and able to produce large format film copies. Manual determination of $\mathrm{X}, \mathrm{Y}$ coordinates has the additional advantage of freeing the CT scanner immediately after the completion of the scan series, minimising required $\mathrm{CT}$ room time. Experience indicates that total CT room time can generally be held under 30 minutes. 
While a small drill hole can be used to biopsy a single target or drain a single cavity, this approach does not allow other angles to be used to reach other target points. More importantly, surface vessels cannot be visualised and properly coagulated, unless a burrhole is made.

Choice of biopsy instruments involves striking a compromise between small size for safety and larger size to ensure obtaining adequate tissue sample. After numerous trials, consistently good results have been obtained using either a side cutting blunt nosed cannula or a small rongeur for biopsy.

The problems for the neuropathologist posed by smaller specimen size are, to some extent, offset by the ease and safety with which multiple tissue samples can be obtained from various specific areas of interest seen on the CT planning scan. Fewer false negative biopsies should result, and the accuracy in grading heterogenous tumours should improve.

Of particular interest to the neuroradiologist is the fact that zones having varying appearances on CT scan can now be studied histologically, with good spatial correlation. It has been found, for example, that a biopsy of the zone of abnormal enhancement around a radiolucent lesion may in some cases show only non-specific inflammatory changes, rather than neoplasm as one might anticipate.

While skull entry point and target points can now be specified with ease, visualising the exact probe pathway is not feasible. A viewing system with which the entire scan series can be seen in proper three-dimensional orientation is under development. An electronic "probe" can be placed in the image to simulate the biopsy probe's pathway through the various CT scan sections prior to performing the actual procedure. ${ }^{14}$

Therapeutic applications of CT-guided stereotactic methods are emerging, including drainage procedures, stimulation electrode placement, surgical resection of small lesions, CT-guided laser resection of larger masses, and insertion of interstitial sources for radiation therapy. ${ }^{15-18}$

The "BRW" system may be modified quite simply in the future for use with NMR or PET images by changing the material used in the localising rods. The rest of the system could be applied without alteration.

This study has been supported in part by the Department of Radiology, University of Utah Medical Center, Salt Lake City, 84132 (REA). We acknowledge the advice of $\mathrm{Dr} T$ Roberts, Dr MP Heilbrun, and Dr Russell Brown, University of Utah, and neuropathological service of Professor L Duchen and Dr F Scaravilli, Department of Neuropathology. We also thank Mr Trent Wells for his engineering advice and generous loan of apparatus, and Mr P Wallace and Mr G Ray for technical engineering assistance. A preliminary report of this series was presented at the 101 st meeting of the Society of British Neurological Surgeons at Leeds in $1982 .{ }^{19}$

\section{References}

' Koslow M, Abele MG, Griffith RC, Mair GA, Chase NE. Stereotactic surgical system controlled by computed tomography. Neurosurgery 1981;8:72-82.

${ }^{2}$ Perry JH, Rosenbaum AE, Lunsford LD, Swink CA, Zorub DS. Computed tomography/guided stereotactic surgery: conception and development of a new stereotactic methodology. Neurosurgery 1980; 7:376-81.

${ }^{3}$ Cacak R, Law JD. Leksell stereotactic instrument (letter). Neurosurgery 1981;8:510.

${ }^{4}$ Boethius J, Bergstrom M, Freitz T, Ribbe T. CT localization in Stereotactic Surgery. Appl Neurophysiol 1980;43:164-9.

${ }^{5}$ Mundinger F, Birg W, Klar M. Computer-assisted stereotactic brain operations by means including computerized axial tomography. Appl Neurophysiol 1978;41:169-82.

' Penn RD, Whisler WW. Smith CA, Yasnoff WA. Stereotactic surgery with image processing of computerized tomographic scans. Neurosurgery 1978;3: 157-63.

${ }^{7}$ Brown RA. A Stereotactic head frame for use with CT body scanners. Invest Radiol 1979;14:300-4.

${ }^{8}$ Roberts TS, Brown R. Technical and Clinical Aspects of CT-Directed Stereotaxis. Appl Neurophysiol 1980; 43:170-1.

${ }^{9}$ Brown RA. A Computerized tomography-computer graphics approach to stereotaxic localization. $J$ Neurosurg 1979;50:715-20.

${ }^{10}$ Brown RA, Roberts TS, Osborn AG. Stereotaxic frame and computer software for CT-directed neurosurgical localization. Invest Radiol 1980;15:308-12.

"Brown RA, Roberts T, Osborn AG. Simplified CTguided stereotaxic biopsy. AJNR 1981;2:181-4.

12 Broggi G, Franzini A. Value of serial sterotactic biopsies and impedance monitoring in the treatment of deep brian tumours $J$ Neurol Neurosurg Psychiatry $1981 ; 44: 397-401$.

${ }^{13}$ Ostertag CB, Mennel HD, Kiessling M. Stereotactic biopsy of brain tumors. Surg Neurol 1980;14:275-83.

${ }^{14}$ Anderson RE, Baxter B, Hitchner L, Shorthill R, Johnson SH. Three Dimensional Viewing System for Tomographic Scan Interpretation Radiology (in press).

${ }^{15}$ Higgins AC, Nashold BS. Stereotactic Evacuation of Large Intracerebral haematoma. Appl Neurophysiol 1980;43:96-103.

${ }^{16}$ Sheldon CH, McCann I, Jacques S, et al. Development of a computerized microstereotaxic method for localization and removal of minute CNS lesions under direct 3-D vision $J$ Neurosurg 1980;52:21-7. 
${ }_{17}$ Kelly PJ, Alker IG. A Method for Stereotactic Laser Microsurgery in the treatment of Deep-seated CNS Neoplasms. Appl Neurophysiol 1980;43:210-15.

${ }_{18}$ Mundinger F, Ostertag CB, Bing W, Weigel K. Stereotactic Treatment of Brain Lesions. Appl
Neurophysiol 1980;43:198-204.

19 Thomas DGT, Anderson RE, du Boulay G. CT-directed stereotactic surgery with the Brown-Roberts-Wells (BRW) System. J Neurol Neurosurg Psychiatry 1983;46:369-70. 